\title{
Development of an opening-tearing mode fracture system for composite materials ${ }^{a}$
}

\author{
A. Szekrényes ${ }^{1}$ \\ ${ }^{1}$ Budapest University of Technology and Economics, Department of Applied Mechanics, 1111 \\ Budapest, Muegyetem rkp. 5, Hungary
}

\begin{abstract}
In this paper the mixed-mode I/III prestressed split-cantilever beam fracture specimen [1,2] is developed, which combines the mode-III modified split-cantilever beam [1] and the well-known double-cantilever beam [3] specimens using a special rig. The most important feature of the novel beam-like specimen is that it is able to provide any combinations of the mode-I and mode-III energy release rates. If only crack propagation onset is involved then the mixed-mode I/III prestressed split-cantilever beam specimen can be used to obtain the fracture criterion of transparent composite materials in the $G_{I}-G_{I I I}$ plane in a relatively simple way.
\end{abstract}

\section{Introduction}

One of the most important damage mechanisms in laminated composite materials is the interlaminar fracture (also known as delamination fracture).

Considering the linear elastic fracture mechanics (LEFM) [e.g.:1] three basic types of the interlaminar fracture are known: mode-I (opening), mode-II (sliding or in-plane shear) and the mode-III (tearing or anti-plane shear). The major part of the literature deals with the mode-I, mode-II and the mixed-mode I/II cases [2]. In the last years the attention of scientists was focused on even the the mode-III fracture of composites. One of the available fracture mechanical configurations for mode-III delamination is the modified split-cantilever beam (MSCB) $[3,4]$. If we combine the MSCB with common double-cantilever beam (DCB) specimen in accordance with the theory of prestressed composite beams [5], we obtain an efficient mixed-mode I/III fracture mechanical tool.

\section{2 the PSCB specimen for mixed-mode I/III cracking}

Figure 1 shows the concept of the prestressed split-cantilever beam (PSCB ${ }_{\mathrm{I} / \mathrm{III}}$ ) specimen, which is the combination of the DCB and MSCB systems. Figure 2 schematically depicts the grips of the MSCB system and the prestressed specimen. The specimen is prestressed with steel roller, this way we fix the mode-I part of the energy release rate (ERR). Then we put the specimen between the grips of the MSCB specimen. The two grips transfer a scissor-like load to the specimen, which provides

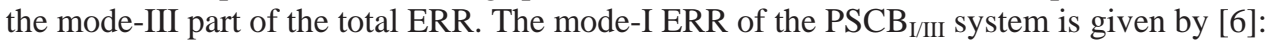

a e-mail : szeki@mm.bme.hu

This is an Open Access article distributed under the terms of the Creative Commons Attribution-Noncommercial License 3.0, which permits unrestricted use, distribution, and reproduction in any noncommercial medium, provided the original work is properly cited. 


$$
G_{I}=\frac{h^{3} E_{11} d_{0}^{2}}{64 a^{4}} \frac{\left[12+f_{W 2}+f_{T}+f_{S V}\right]}{\left[1+\left(f_{W 1}+f_{T}+f_{S V} / 2\right) / 4\right]^{2}},
$$

where the factors are :

$$
\begin{gathered}
f_{W 1}=5.07\left(\frac{h}{a}\right)\left(\frac{E_{11}}{E_{22}}\right)^{\frac{1}{4}}+8.58\left(\frac{h}{a}\right)^{2}\left(\frac{E_{11}}{E_{22}}\right)^{\frac{1}{2}}+2.08\left(\frac{h}{a}\right)^{3}\left(\frac{E_{11}}{E_{22}}\right)^{\frac{3}{4}}, \\
f_{T}=\frac{1}{k}\left(\frac{h}{a}\right)^{2}\left(\frac{E_{11}}{G_{12}}\right), \\
f_{S V}=\frac{12}{\pi}\left(\frac{h}{a}\right)\left(\frac{E_{11}}{G_{12}}\right)^{\frac{1}{2}}, \\
f_{W 2}=10.14\left(\frac{h}{a}\right)\left(\frac{E_{11}}{E_{22}}\right)^{\frac{1}{4}}+8.58\left(\frac{h}{a}\right)^{2}\left(\frac{E_{11}}{E_{22}}\right)^{\frac{1}{2}},
\end{gathered}
$$

where $d_{0}$ is the diameter of the steel roller, $h$ is the half thickness of the specimen, $b$ is the width of the specimen, $a$ is the crack length, $E_{11}$ is the flexural modulus and $G_{12}$ is the shear modulus in the $x$ $y$ and planes, respectively (see Figure 2).

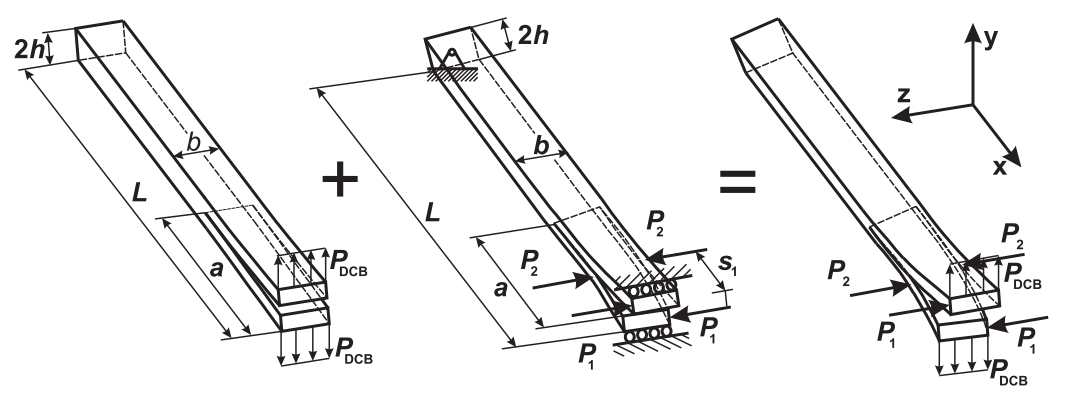

Fig. 1. The concept of the mixed-mode I/III prestressed split-cantilever beam specimen.

Based on Eq. (5) the mode-III ERR of the $\operatorname{PSCB}_{\mathrm{I} / I I}$ system is given by [6]:

$$
G_{I I I}=\frac{12 P_{M S C B}^{2} a^{2}}{b^{4} h E_{11}}\left[f_{E B 2}+f_{T I M 2}+f_{F T 2}+f_{S-V 2}\right],
$$

where $P_{\mathrm{MSCB}}$ is the applied load of the MSCB specimen, furthermore the factors are:

$$
\begin{gathered}
f_{E B 2}=1-2\left(\frac{s_{1}+s_{2}}{a}\right)+\left(\frac{s_{1}+s_{2}}{a}\right)^{2}, \\
f_{\text {TIM } 2}=0.1\left(\frac{b}{a}\right)^{2}\left(\frac{E_{11}}{G_{13}}\right),
\end{gathered}
$$




$$
\begin{gathered}
f_{F T 2}=0.06 \frac{1}{\varsigma}\left(\frac{b}{a}\right)^{2}\left(\frac{E_{11}}{G_{12}}\right), \\
f_{S-V 2}=0.32\left(1-\frac{s_{1}+s_{2}}{a}\right)\left(\frac{b}{a}\right)\left(\frac{E_{11}}{G_{13}}\right)^{\frac{1}{2}}, \\
\varsigma=1-0.63 \mu \frac{h}{b}, \mu=\left(\frac{G_{13}}{G_{12}}\right)^{\frac{1}{2}},
\end{gathered}
$$

where $s_{1}$ and $s_{2}$ are the distances among the loading rollers A, B and C in Figure 2, $G_{13}$ is the shear modulus in the $x-z$ plane.

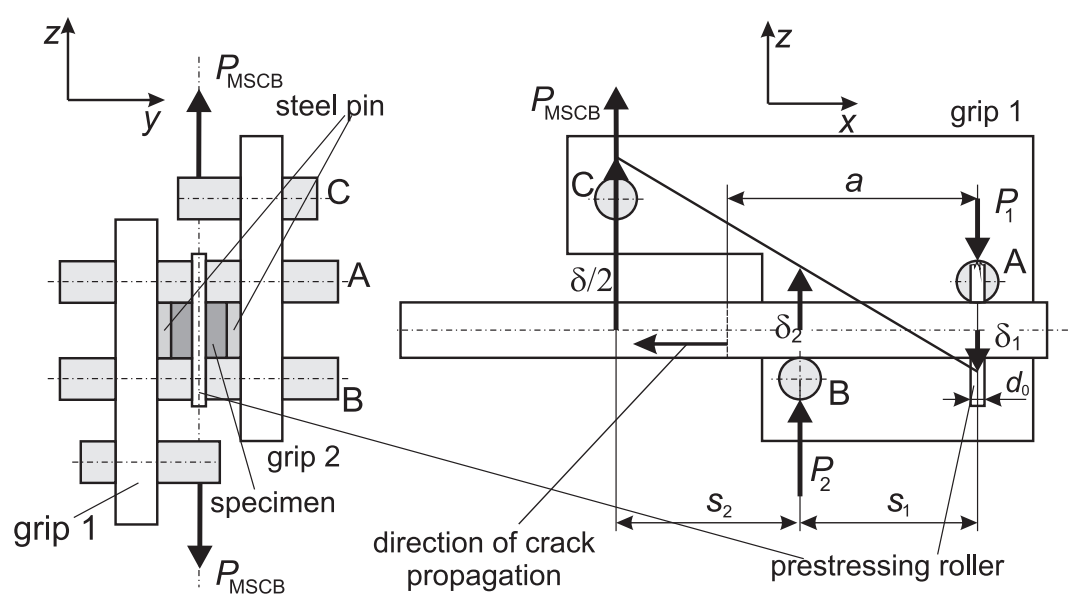

Fig. 2. The grips and the equilibrium of the prestressed split-cantilever beam specimen.

\section{Experiments}

\subsection{Material properties}

The constituent materials of the E-glass/polyester composite were procured from Novia Ltd. The properties of the E-glass fiber are $E=70 \mathrm{GPa}$ and $v=0.27$, and the properties of the unsaturated polyester resin we applied are: $E=3.5 \mathrm{GPa}$ and $v=0.35$. Both were considered to be isotropic. The unidirectional $\left(\left[0^{\circ}\right]_{14}\right)$ E-glass/polyester specimens with thickness of $2 h=6.2 \mathrm{~mm}$, width of $b=12.5$ $\mathrm{mm}$, and fiber-volume fraction of $V_{f}=43 \%$ were manufactured in a special pressure tool. A polyamide (PA) insert with thickness of $0.03 \mathrm{~mm}$ was placed at the midplane of the specimens to make an artificial starting defect. It should be highlighted that this film thickness is higher than the $0.013 \mathrm{~mm}$ recommended in the DCB and MMB test standards [2].

A great advantage of the present E-glass/polyester material is the transparency, which makes it possible to observe the crack initiation visually. The tool was left at room temperature until the specimens became dry. Then the specimens were removed from the tool and were further left at room temperature until 4-6 hours. The specimens were cut to the desired length and were precracked in opening mode of 4-5 $\mathrm{mm}$ by using a sharp blade.

The flexural modulus of the material was determined from a three-point bending test with span length of $2 L=150 \mathrm{~mm}$ using six uncracked specimens with thickness of $2 h=6.2 \mathrm{~mm}$ and width of 
$b=20 \mathrm{~mm}$. The flexural modulus was computed in accordance with a simple beam theory expression: $\delta_{\text {bend }}=P L^{3} /\left(4 b h^{3} E_{11}\right)$, which is the displacement at the point of load introduction. The experiments resulted in $E_{11}=33 \mathrm{GPa}$. In fact the shear deformation was not accounted for, however its contribution to the displacement is very small: $\delta_{\text {shear }}=P L /\left(4 b h k G_{12}\right)$. The additional properties were predicted from simple rules of mixture, in this way $E_{22}=E_{33}=7.2 \mathrm{GPa}, G_{12}=G_{13}=3 \mathrm{GPa}$ and $v_{12}=v_{13}=0.27$ were obtained. Using these values the ratio of the displacements from bending and shear deformation at the center of the specimens is: $(h / L)^{2} \cdot E_{11} /\left(G_{12} k\right)=0.0056$, i.e. the amount of shear deformation is very small and can be neglected. To confirm the assumption that the material is transversely isotropic the specimens were cut along the longitudinal direction in order to obtain very narrow specimens. The narrow specimens were rotated by $90^{\circ}$ about the longitudinal axis compared to the original measurements and the slope of the load-displacement data of the specimens was measured again. These experiments resulted also in $E_{11}=33 \mathrm{GPa}$, i.e. the material was found to be transversely isotropic. The material properties were used in the data reduction process.

\subsection{Double cantilever-beam test}

In the case of the DCB test (Figure 1b) we refer to previous fracture experiments [6] performed in the crack length range of $a=20$ to $150 \mathrm{~mm}$. It has been found that the initiation critical ERR becomes independent of $a$, after $90 \mathrm{~mm}$. The steady-state ERR was $G_{\mathrm{IC}}=412 \mathrm{~J} / \mathrm{m}^{2}$ evaluated by using an IBT scheme. This value will be used in the sequel.

\subsection{Modified split-cantilever-beam test}

For the MSCB measurements four specimens were prepared with $a=105 \mathrm{~mm}$ and $s_{l}=49.26 \mathrm{~mm}$ and $s_{2}=51.15 \mathrm{~mm}$, respectively. Each specimen was put into the loading rig shown in Figure 2, the rig was adjusted in order to eliminate any play of the specimens. Then the specimens were loaded, the load and displacement values were read from the scale of the testing machine and using a mechanical dial gauge. The crack initiation was identified visually, so when the first non-uniformity in the previously straight crack front was observed it was believed to be the point of crack initiation.

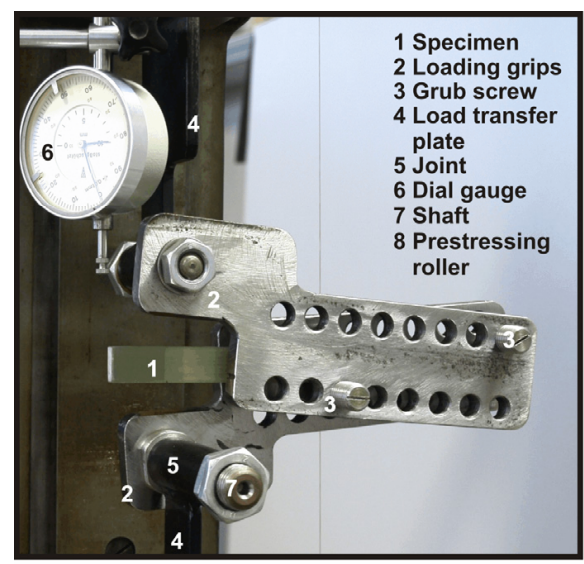

a.

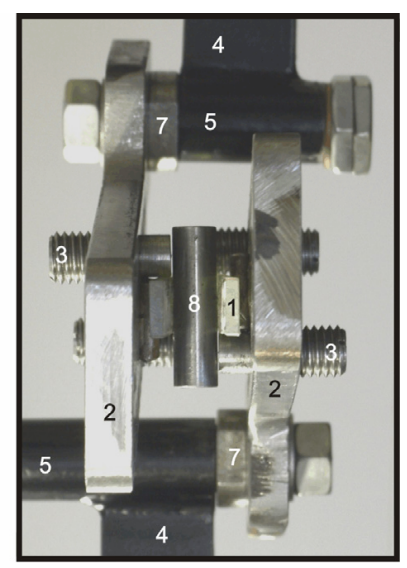

b.

Fig. 3. The experimental equipment of the $\operatorname{PSCB}_{\mathrm{I} / \mathrm{III}}$ specimen. Side view (a) and front view (b).

\subsection{Prestressed split-cantilever-beam test}

The experimental equipment for the $\mathrm{PSCB}_{\mathrm{I} / \mathrm{III}}$ test is demonstrated in Figure 3. The tests were carried out using an Amsler testing machine under displacement control. The crack length of interest was 
$a=105 \mathrm{~mm}$. The critical crack opening displacement measured from the DCB test [6] is about 15-16 $\mathrm{mm}$ (if $a=105 \mathrm{~mm}$ ). Six steel rollers were used including the following diameters: $d_{0}=6,7,8,10,12$ and $13 \mathrm{~mm}$. It was assumed that the crack opening displacements $\left(\delta_{D C B}\right)$ were identical to these values. The specimen arms transmitted a relatively high pressure to the steel roller, therefore the position of the rollers was always stable and no slip along the $x$ axis was observed during the measurements. Similarly to the MSCB tests, we applied four coupons at each steel roller. The loaddeflection data was measured by using the scale of the testing machine and a mechanical dial gauge (see Figure 3). In each case the critical load at crack initiation was determined.

\section{Results and discussion}

It will be shown subsequently that the stiffness, the compliance and the mode-III ERR of the $\mathrm{PSCB}_{\mathrm{I} / \mathrm{III}}$ specimen are identical (with a very good approximation) to those of the MSCB specimen.

\subsection{Load and displacement}

Figure 4a shows a recorded load-displacement curve for the $\mathrm{PSCB}_{\mathrm{I} / \mathrm{III}}$ specimen if $d_{0}=8.0 \mathrm{~mm}$. The response follows essentially a linear relation. The $\mathrm{PSCB}_{\mathrm{I} / \mathrm{III}}$ test was performed according to the followings. The onset of crack advance was identified by visual observations. In each case four specimens were tested, one of them was used to investigate the crack front. The other three specimens were loaded continuously and the crack initiation was observed in situ. So, the former specimen was loaded subsequently, at some points, where the initiation was expected the specimen was relieved, removed from the rig and the crack front was photographed. When the first nonuniformity was observed, then this point was denoted to be the point of fracture initiation. The results of this process are demonstrated in Fig. $8 \mathrm{~b}$ for the $\mathrm{PSCB}_{\mathrm{I} / \mathrm{III}}$ system iw $d_{0}=8.0 \mathrm{~mm}$.

a.

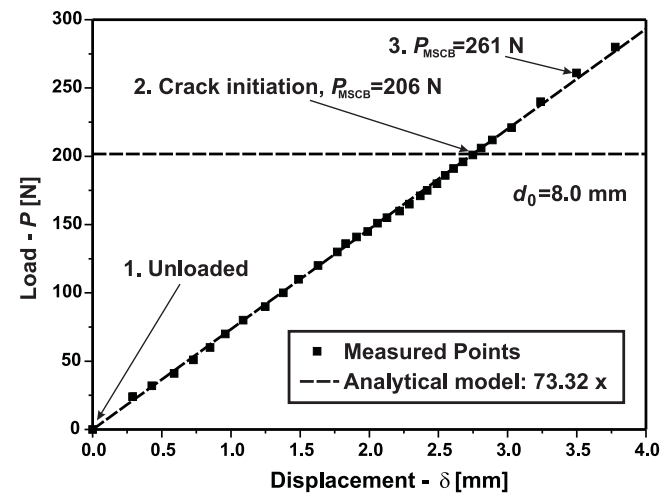

b.

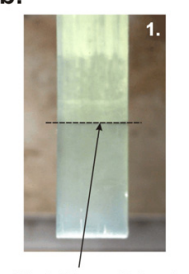

Straight crack front

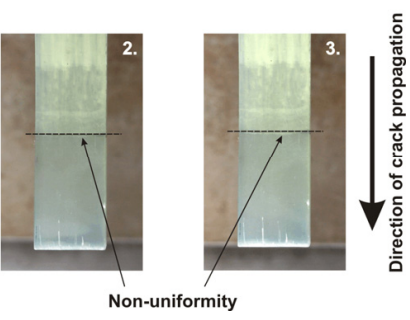

Fig. 4. Load-displacement curve of the $\mathrm{PSCB}_{\mathrm{I} / \mathrm{III}}$ system if $d_{0}=8.0 \mathrm{~mm}$ (a). The identification of crack initiation during the fracture process (b).

The maximum difference was $10.5 \%$ between the measured and calculated slopes, consequently the prestressed state does not influence noticeably the stiffness of the system and the compliance of the $\mathrm{PSCB}_{\mathrm{I} / \mathrm{III}}$ can be assumed to be equal to that of the MSCB system. On the other hand the effect of friction between the steel roller and the specimen arms on the load-displacement response of the system is insignificant.

\subsection{Data reduction}

To reduce the measured data Eqs. (1)-(11) were used. 


\subsubsection{Double-cantilever beam}

Based on a previous paper the mode-I critical ERR was measured to be $G_{\mathrm{IC}}=412 \mathrm{~J} / \mathrm{m}^{2}$ using the IBT scheme [6].

\subsubsection{Modified split-cantilever beam}

Replacing $P_{M S C B}$ with $P_{I I I}$ in Equation (6) gives the improved solution for the MSCB coupon, where $P_{I I I}$ is the critical load value at crack onset. The IBT resulted in $G_{\text {IIIC }}=114.5 \pm 16.0 \mathrm{~J} / \mathrm{m}^{2}$.

\subsubsection{Prestressed split-cantilever beam}

The improved analytical solutions are given by Eqs. (1) and (11) for the $\mathrm{PSCB}_{\mathrm{I} / \mathrm{III}}$ system.

\subsection{Critical energy release rates}

The critical mode-I, mode-III and the mixed-mode I/III ERRs at crack initiation and the mode mix calculated by the IBT are given in Table 1. The geometries tested had properties of $a=105 \mathrm{~mm}$, $2 h=6.2 \mathrm{~mm}, s_{1}=49.26 \mathrm{~mm}, s_{2}=51.15 \mathrm{~mm}$ and $L=150 \mathrm{~mm}$ and at each value of the diameter of the prestressing roller $\left(d_{0}\right)$ four coupons were used.

Table 1. Critical energy release rates calculated by improved beam theory (IBT).

\begin{tabular}{l|lllllllll}
\hline & $d_{0}$ & $0(\mathrm{MSCB})$ & 6 & 7 & 8 & 10 & 12 & 13 & $\sim 15(\mathrm{DCB})$ \\
\hline \multirow{5}{*}{$\mathrm{IBT}$} & $G_{\mathrm{III}} / G_{\mathrm{I}}$ & $\infty$ & 2.01 & 1.32 & 0.82 & 0.42 & 0.17 & 0.11 & 0.00 \\
& & - & \pm 0.20 & \pm 0.22 & \pm 0.10 & \pm 0.06 & \pm 0.02 & \pm 0.01 & - \\
& \multirow{2}{*}{$G_{\mathrm{I}}\left[\mathrm{J} / \mathrm{m}^{2}\right]$} & 0.0 & 47.5 & 64.7 & 84.5 & 132.1 & 190.2 & 223.2 & 412.0 \\
& $G_{\mathrm{III}}\left[\mathrm{J} / \mathrm{m}^{2}\right]$ & 114.8 & 95.6 & 85.3 & 69.5 & 54.9 & 33.0 & 24.8 & 0.0 \\
& & \pm 16.0 & \pm 9.7 & \pm 14.5 & \pm 8.8 & \pm 7.3 & \pm 3.2 & \pm 1.8 & - \\
& & 114.8 & 143.2 & 150.1 & 154.0 & 187.0 & 223.2 & 248.0 & 412.0
\end{tabular}

\subsection{Fracture envelopes}

In order to construct a fracture envelope in the $G_{I^{-}} G_{\text {III }}$ plane we apply the two most popular criteria, which are frequently used in studies related to fracture characterization of composite materials under mixed-mode I/II condition. It is assumed that they can be applied also for mixed-mode I/III fracture. In accordance with the power criterion the following relation may be established between the mode-I and mode-III ERRs [7]:

$$
\left(\frac{G_{I}}{G_{I C}}\right)^{p_{1}}+\left(\frac{G_{I I I}}{G_{I I I C}}\right)^{p_{2}}=1
$$

Williams' criterion [6,7] recommends the following expression for the relation between the mode-I and mode-III ERRs:

$$
\left(\frac{G_{I}}{G_{I C}}-1\right)\left(\frac{G_{I I I}}{G_{I I I C}}-1\right)-I_{i}\left(\frac{G_{I}}{G_{I C}}\right)\left(\frac{G_{I I I}}{G_{I I I C}}\right)=0,
$$

where $I_{\mathrm{i}}$ is the interaction parameter between the mode-I and mode-III ERRs. If $I_{\mathrm{i}}=0$ then there is no interaction. Also, if $I_{\mathrm{i}}=1$ then Equation (13) states a simple addition. In Eqs. (12)-(13) $G_{\mathrm{IC}}$ is the 
critical ERR under pure mode-I (calculated from the data of the DCB specimen), $G_{\text {IIIC }}$ is the modeIII critical ERR (calculated from the data of the MSCB specimen). The results of the $\mathrm{PSCB}_{\mathrm{I} / \mathrm{III}}$ test listed in Table 1 were used to provide six additional points in the $G_{\mathrm{I}}-G_{\mathrm{III}}$ plane. The power parameters $\left(p_{1}, p_{2}\right)$ in Equation (12) and the interaction parameter $\left(I_{\mathrm{i}}\right)$ in Equation (13) were determined by a curve-fit technique by applying the ORIGINPRO 7.0 code.

The fracture envelope calculated by the IBT method is displayed in Figure 5a. The main conclusion is that there is some interaction between the mode-I and mode-III ERRs, although the relation between $G_{\mathrm{I}}$ and $G_{\mathrm{III}}$ is almost linear. The scatter is also in reasonable ranges and it decreases with the increase of $G_{\mathrm{IC}}$. Overall, the difference between the power and Williams' criteria is negligible; both describe the same failure locus.

a.

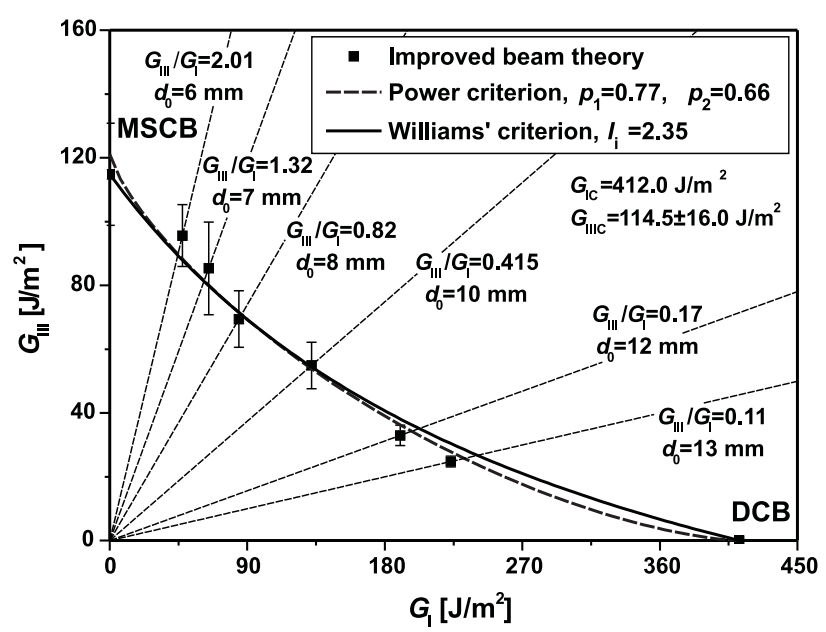

b.

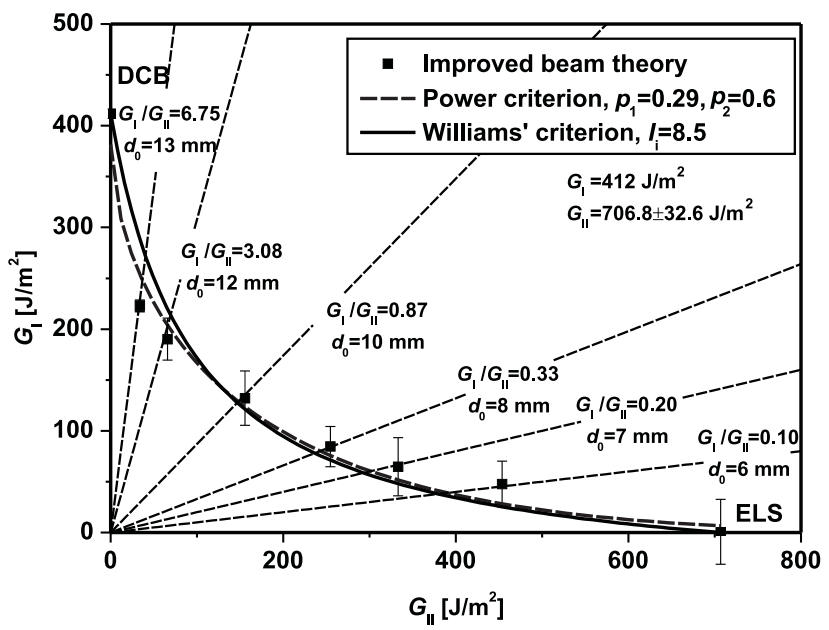

Fig. 5. Fracture envelopes in $G_{\mathrm{I}^{-}} G_{\mathrm{III}}$ (a) and $G_{\mathrm{I}^{-}} G_{\mathrm{II}}$ (b) planes

In a previous work fracture envelope in the $G_{\mathrm{I}} G_{\text {II }}$ plane wad constructed by the mixed-mode I/II version of the PENF specimen $\left(\mathrm{PENF}_{\mathrm{I} / \mathrm{II}}\right)$ for the same E-glass/polyester material [6]. A similar experimental study resulted in a concave envelope in the $G_{\mathrm{I}}-G_{\mathrm{II}}$ plane as it is shown in Figure $5 \mathrm{~b}$. It is important to note, that the envelopes in Figure $5 \mathrm{~b}$ were determined using specimens with $a=55$ $\mathrm{mm}$, while the present one in Figure 5a is for the case of $a=105 \mathrm{~mm}$. Based on the comparison 
between Figures $5 \mathrm{a}$ and $\mathrm{b}$ we may conclude that the material proves similar behavior in the $G_{\mathrm{I}^{-}} G_{\mathrm{II}}$, and the $G_{\mathrm{I}}-G_{\text {III }}$ plane. It is also important to note that interaction takes place in both cases.

\section{Conclusions}

In this work the mixed-mode I/III version of the prestressed split-cantilever beam specimen was developed for interlaminar fracture testing of laminated transparent composite materials. Apart from the MSCB and the traditional DCB tests the $\mathrm{PSCB}_{\mathrm{I} / I I}$ specimen was used to obtain the mixed-mode I/III energy release rate at crack propagation onset including six different mode ratios. To perform the experiments unidirectional E-glass/polyester specimens were manufactured. An improved beam model was recommended for the evaluation of both the mode-I and mode-III energy release rates

Based on the performed experimental work the fracture envelope of the present material was determined indicating some interaction between $G_{\mathrm{I}}$ and $G_{\mathrm{III}}$.

The $\mathrm{PSCB}_{\mathrm{I} / \mathrm{III}}$ specimen offers several advantages. First of all, it incorporates the traditional beam-like specimen geometry. Second, it was shown that the $\mathrm{PSCB}_{\mathrm{I} / \mathrm{III}}$ specimen is able to produce any mode ratio at crack propagation onset. The drawbacks of the PSCB specimen are the low compliance values; the mode ratio changes with the crack length and the applied load, so the method is recommended mainly for the testing of transparent composite materials. Moreover the mode ratio can not be calculated without performing experiments (i.e. it can not be designated before the test), involving the fact that the mode ratio will depend on the definition of the crack initiation and the accuracy of the measurement of the load and crack length.

More research is needed to reduce the drawbacks of the test and to develop new data reduction schemes.

\section{Acknowledgements}

This paper was supported by the János Bolyai Research Scholarship of the Hungarian Academy of Sciences and the National Science and Research Fund (OTKA) under Grant No. T34040.

\section{References}

1. T.L. Anderson. Fracture Mechanics - Fundamentals and Applications. Third Edition. CRC Press, Taylor \& Francis Group, Boca Raton, London, New York, Singapore, (2005)

2. A.J.Brunner, B.R.K.Blackman, P. Davies. A status report on delamination resistance testing of polymer-matrix composites. Eng Fract Mech 75 (2008) 2779-2794.

3. P. Robinson, Q.D. Song. The development of an improved mode III delamination test for composites. Compos Sci Technol 52 (1994):217-233.

4. D. Cicci, F. Sharif, M.T. Kortschot. Data reduction for the split cantilever beam mode III delamination test. In: Proceedings, ACCM 10, Whistler, British Columbia, Canada, 14-18 August (1995)

5. A. Szekrényes. Prestressed fracture specimen for delamination testing of composites. Int $J$ Fracture 139 (2006) 213-237.

6. A. Szekrényes. Interlaminar fracture analysis in the $G_{\mathrm{I}}-G_{\mathrm{III}}$ plane using prestressed transparent composite beams. Compos Part A-Appl S 40(10) (2009) 1621-1631.

7. S. Hashemi, J. Kinloch, J.G. Williams Mechanics and mechanisms of delamination in a poly(ether sulphone)-fibre composite. Compos Sci Technol 37 (1990) 429-462. 